\title{
Genetic polymorphisms of LPL and HL and their association with the performance of Chinese sturgeons fed a formulated diet
}

\author{
Y. He ${ }^{1 *}$, D. Shen ${ }^{1 *}$, X.F. Liang ${ }^{1}$, R.H. Lu ${ }^{1}$ and H. Xiao ${ }^{2}$ \\ ${ }^{1}$ College of Fisheries, Huazhong Agricultural University, Wuhan, China \\ ${ }^{2}$ Institute of Chinese Sturgeon Research, \\ China Three Gorges Project Corporation, Yichang, China \\ *These authors contributed equally to this study. \\ Corresponding author: X.F. Liang \\ E-mail: xufang_liang@hotmail.com
}

Genet. Mol. Res. 12 (4): 4559-4566 (2013)

Received February 1, 2013

Accepted September 10, 2013

Published October 15, 2013

DOI http://dx.doi.org/10.4238/2013.October.15.4

\begin{abstract}
It is very important to investigate the reasons for the large individual differences in individual performance of food acceptance when using formulated diets for the successful culture of larvae and juveniles of the Chinese sturgeon Acipenser sinensis. Genetic differences of the mitochondrial control region were investigated by direct sequencing in two groups of Chinese sturgeon, which were apt to accept or refuse formulated diets. Among 968-bp sequences, 111 variable sites were identified. One variable site showed close association with the individual performance of specimens fed with formulated diets. The commercial diet for Chinese sturgeons usually contains high levels of lipids. Lipoprotein lipase (LPL) and hepatic lipase (HL) are two members of the lipase gene family, which are essential for the utilization of dietary lipid. Single nucleotide polymorphisms (SNPs) in intron 7 were detected in the two experimental groups of Chinese
\end{abstract}


sturgeons. We were able to demonstrate that one SNP in the LPL gene and one SNP in the HL gene showed close association with the performance of sturgeons on the formulated diet.

Key words: Chinese sturgeon Acipenser sinensis; Lipoprotein lipase; Single nucleotide polymorphism; Mitochondrial control region; Hepatic lipase; Performance on formulated diet

\section{INTRODUCTION}

Chinese sturgeon, Acipenser sinensis, an anadromous fish, is approved by the Chinese government red list (Wei et al., 1997) as a class I endangered species. Juveniles hatch in the Yangtze River, migrate to the sea, and return as adults to spawn at the age of 8 to 10 years (Wei et al., 1997). Historical spawning areas have disappeared because of the Gezhouba and ThreeGorge Dams being built across the Yangtze River, which is approximately $1000 \mathrm{~km}$ below Yibin City. Currently, the survival of Chinese sturgeon is dependent on artificial propagation, but intensive spawning and larval rearing have only been partially successful. Zooplankton and fingerling are the priority foods for Chinese sturgeon in the wild, and these fishes refuse to eat formulated feed. However, experiments with long-term cultivation suggest that Chinese sturgeons can be domesticated to feed on commercial feedstuffs, although there are some individual differences; therefore, the survival rates often fluctuate (Xiao et al., 1999; Qian et al., 2002). Hence, it is very important to investigate the reasons for the large individual differences in larvae and juvenile cultures in accepting formulated diets.

Genes that regulate metabolism and energy partitioning have the potential to influence the performance when formulated diets are used for farmed specimens, as do polymorphisms within these genes. The commercial diet usually contains high levels of lipids. Lipoprotein lipase (LPL) and hepatic lipase (HL) are two members of the lipase enzyme family, which are essential for the utilization of dietary lipid (Wong and Schotz, 2002; Mukherjee, 2003). The two plasma lipases share high degrees of structural similarity with each other but play different roles in lipid metabolism.

LPL participates in the cellular uptake of plasma chylomicrons and very-low-density lipoprotein in various kinds of extrahepatic tissue (Mead et al., 2002). LPL genes have been characterized in a number of higher vertebrates, including mammals (Cooper et al., 1989; Raisonnier et al., 1995). LPL is synthesized in various tissues, and gene expression is regulated by the physiological, nutritional, and developmental states of animals in a tissue-specific manner (Cooper et al., 1989; Semenkovich et al., 1989). HL is primarily synthesized in the liver and involved in chylomicron-remnant and high-density-lipoprotein metabolism (SantamarinaFojo et al., 1998). In mammals, HL activity has been detected in the liver and several extrahepatic tissues, including the adrenal gland and ovary (Santamarina-Fojo et al., 1998). In the present study, genetic variations of the mitochondrial control region were investigated by direct sequencing in two groups of Chinese sturgeon that were apt to accept or refuse formulated diets. The intron 7 of the two enzyme genes were further obtained and characterized, and their single nucleotide polymorphisms (SNPs) and the association with performance on formulated diet were determined, and we believe that these findings will provide a better understanding of the individual differences in the acceptance of formulated diets. 


\section{MATERIAL AND METHODS}

Chinese sturgeon juveniles (total length, 15 to $27 \mathrm{~cm}$ ) were obtained from the Chinese Sturgeon Research Institute, China Three Gorges Project Corporation (Yichang, China). Half of the experimental fishes that accepted formulated diets were reared in an indoor tank (AF group), and the other half that refused formulated diets were reared in another indoor tank (RF group). One hundred individuals of Chinese sturgeon juveniles (total length, 7 to $12 \mathrm{~cm}$ ) were selected to be fed with a mixture of commercial feedstuffs and fishworms, with the latter component in inverse proportion, decreasing daily until it reached zero a week later. Then, these juveniles were fed pure commercial feedstuffs for 1 week, after which the AF group was selected as the one that grew faster and appeared much bigger and fatter than the others. The rest of the juveniles that appeared thin and small were again fed a mixture of commercial feedstuffs and fishworms. After repeating this procedure 4 times, the fish in the RF group were finally selected as the ones that refused to eat commercial feedstuffs and appeared very thin and small. In total, both the AF and RF groups consisted of 19 individuals. All these 38 fishes were killed, and the liver tissues were immediately dissected for RNA and DNA isolation.

Genomic DNA was isolated using the Blood \& Cell Culture DNA Kit (Qiagen, USA) according to manufacturer recommendations. Primers for polymerase chain reaction (PCR) amplification of the mitochondrial D-loop and intron 7 of the Chinese sturgeon LPL and HL genes are listed in Table 1. PCR was performed in a $50-\mu \mathrm{L}$ reaction containing 200 to $300 \mathrm{ng}$ genomic DNA. The following cycle was used for amplification: denaturation for 1 min at $94^{\circ} \mathrm{C}$, annealing for $1 \mathrm{~min}$ at $57^{\circ} \mathrm{C}$, and extension for $1 \mathrm{~min}$ at $72^{\circ} \mathrm{C}$, repeated for 30 cycles, with an additional $3-\mathrm{min}$ initial denaturation at $94^{\circ} \mathrm{C}$ and a 5 -min final extension at $72^{\circ} \mathrm{C}$. The genomic PCR products were directly used for sequencing. The Vector NTI suite 6.0 was used to analyze sequence homology.

\begin{tabular}{|c|c|}
\hline Name of primer & Sequence of primer \\
\hline \multicolumn{2}{|l|}{ SNP } \\
\hline CON01F & 5'-AAATCCTTCCTAGCGCC-3' \\
\hline CON02R & 5'-TTAGCAAGGCGTCTTGG-3' \\
\hline LPL03F & 5'-ATCAGCCAATCCTGTTGTCTCTGTA-3' \\
\hline LPL04R & 5'-CCTTCACTCTGAGCTTGC-3' \\
\hline HL03F & 5'-ATCACTACCAGTTCAAGATCC-3' \\
\hline HL04R & 5'-CAGCCTTGACCCGGATTCT -3' \\
\hline
\end{tabular}

\section{RESULTS AND DISCUSSION}

Genetic differences in the mitochondrial control region were investigated by direct sequencing of the genetic material from the two groups of Chinese sturgeon that accepted or refused formulated diets. Among 968-bp sequences, 111 variable sites were identified (Tables 2 and 3). One variable site showed close association with the individual performance of specimens fed with formulated diets (Figure 1). 
Table 2. Polymorphic site analysis of the D-loop, lipoprotein lipase (LPL), and hepatic lipase (HL) in the two groups of Chinese sturgeon that accepted or refused formulated diets.

\begin{tabular}{llccccc}
\hline Gene & Loci & Total number of sites & Invariable sites & Variable sites & Singleton variable sites & Parsimony informative sites \\
\hline D-loop & Genome & 968 & 772 & 111 & 53 & 58 \\
LPL & Intron 7 & 351 & 256 & 86 & 27 & 59 \\
HL & Intron 7 & 880 & 741 & 139 & 80 & 59 \\
\hline
\end{tabular}

Table 3. Demographic parameters estimated from the D-loop, lipoprotein lipase (LPL), and hepatic lipase (HL) in the two groups of Chinese sturgeon that accepted or refused formulated diets.

\begin{tabular}{llcc}
\hline Gene & Population & $\mathrm{K}$ & $\mathrm{Pi}$ \\
\hline D-loop & RF group & 24.267 & 0.02748 \\
& AF group & 28.311 & 0.03206 \\
LPL & RF group & 17.883 & 0.05095 \\
& AF group & 17.661 & 0.05032 \\
HL & RF group & 14.444 & 0.01641 \\
& AF group & 17.673 & 0.02008 \\
\hline
\end{tabular}

$\mathrm{K}=$ average number of nucleotide difference; $\mathrm{Pi}=$ nucleotide diversity. $\mathrm{AF}$ group $=$ group of Chinese sturgeon that accepted formulated diets; RF group = group of Chinese sturgeon that refused formulated diets.

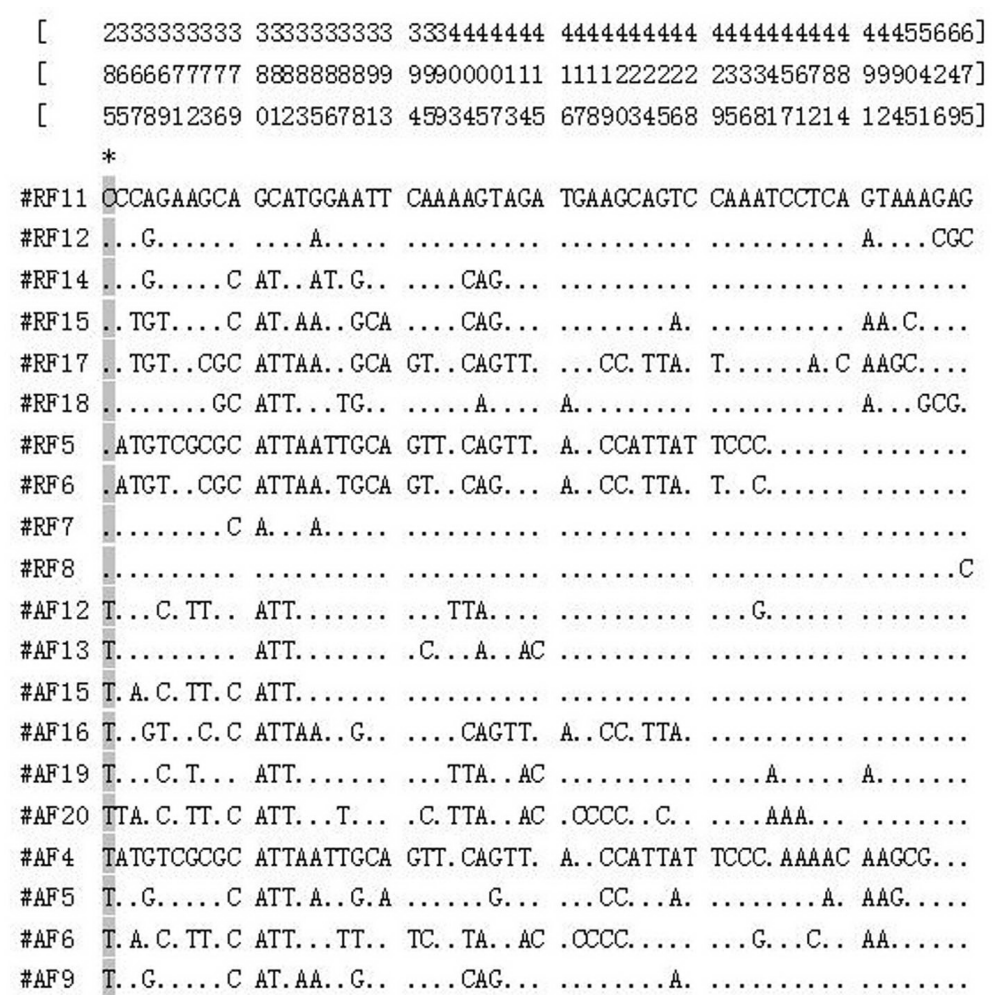

Figure 1. Variations in the mtDNA control region of Chinese sturgeon. The numerals at the top indicate the location of the variable sites in the sequence analysis. The sequence names starting with 'RF' are from the group that refused formulated diets. The sequence names starting with 'AF' are from the group that accepted formulated diets. Dots indicate identity with the RF11 sequence. Asterisk indicates diagnostic site. 
We detected SNPs in the intron 7 of the two lipase genes in the two experimental groups of Chinese sturgeons. Consistent with the genetic differences of the mitochondrial control region, one SNP each in the LPL and HL genes showed close association with diet acceptance using the same formulated diet (Figures 2 and 3).

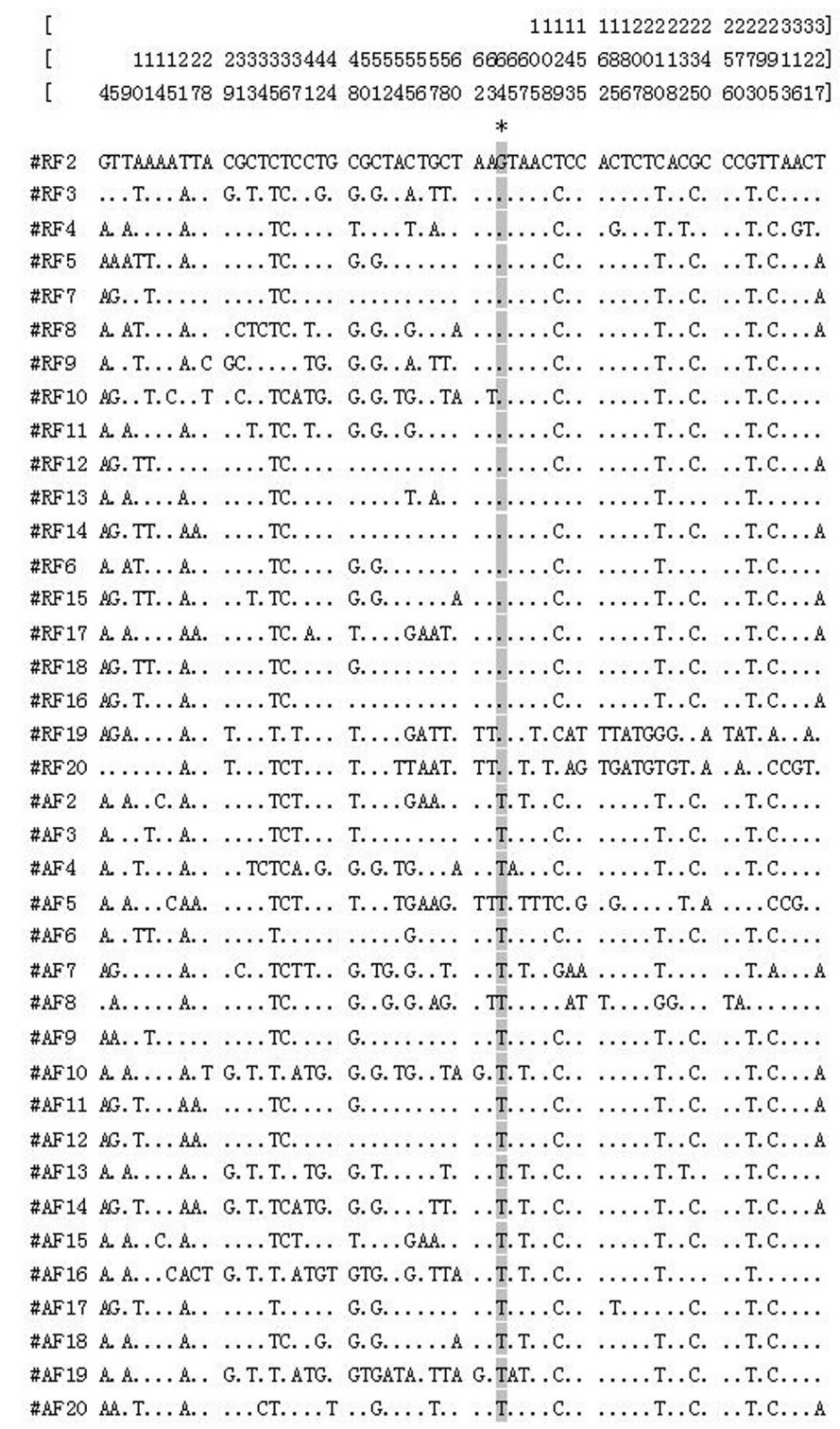

Figure 2. Variations in the intron 7 of the Chinese sturgeon lipoprotein lipase (LPL) gene. The numerals at the top indicate the location of the variable sites in the sequence analysis. The sequence names starting with 'RF' are from the group that refused formulated diets. The sequence names starting with 'AF' are from the group that accepted formulated diets. Dots indicate identity with the RF2 sequence. Asterisk indicates diagnostic site. 


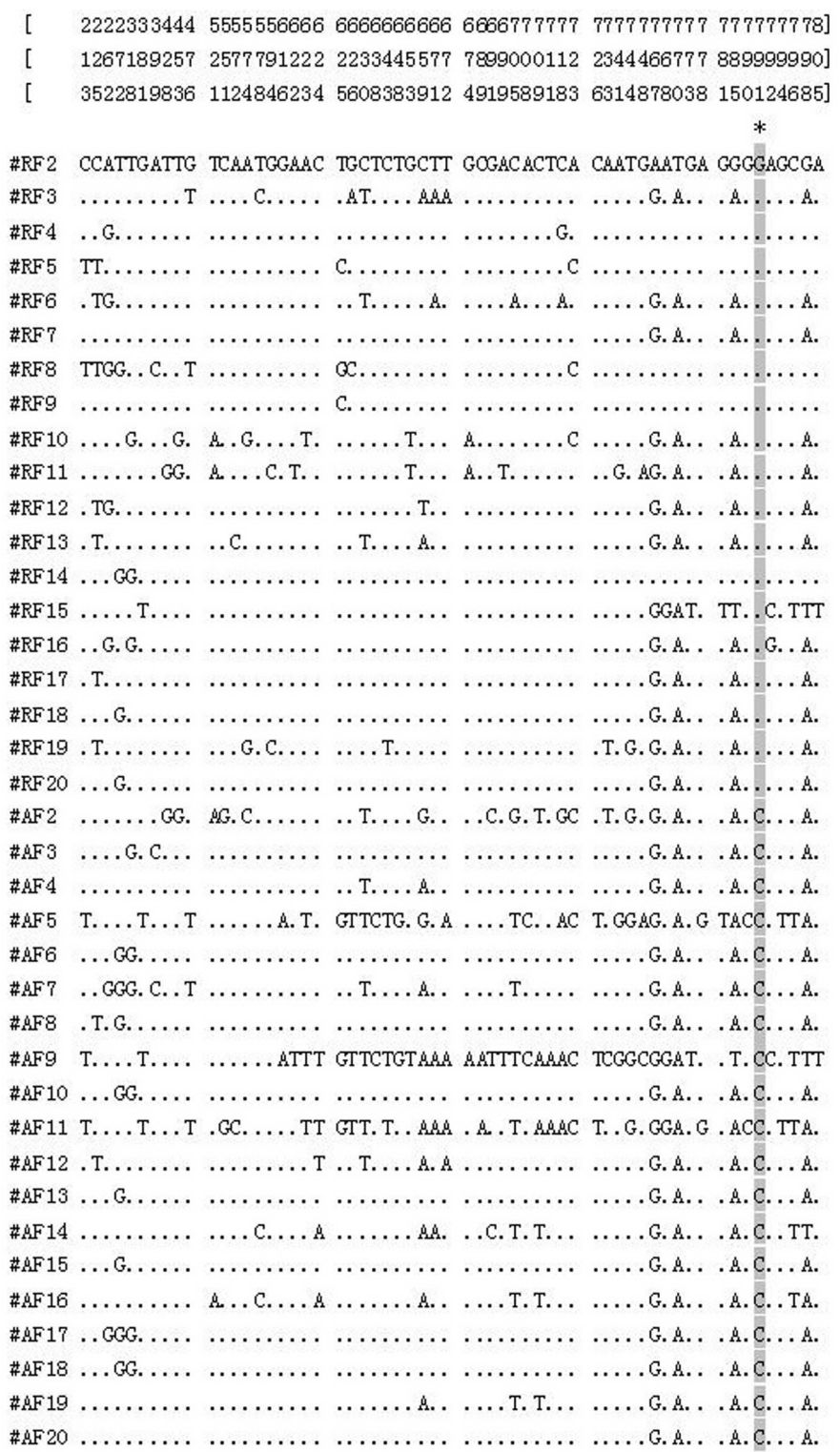

Figure 3. Variations in the intron 7 of the Chinese sturgeon hepatic lipase (HL) gene. The numerals at the top indicate the location of the variable sites in the sequence analysis. The sequence names starting with 'RF' are from the group that refused formulated diets. The sequence names starting with 'AF' are from the group that accepted formulated diets. Dots indicate identity with the RF2 sequence. Asterisk indicates diagnostic site.

Diet habits can form gradually with learned experience; therefore, most cultivated teleost fishes can learn to accept artificial diets without difficulty (Brown, 1985; Warburton, 2003). In addition, although the environmental factor is a major component of behavioral changes with learned experience, the impact of the genetic factor must also be considered 
(Carvalho et al., 2004; Jackson et al., 2004; Peňa et al., 2004; Snickars et al., 2004; Stoner, 2004; Carton, 2005; Hara, 2006; Liang et al., 2008). In contrast with learning experience, unlearned genetic predispositions should be extremely important to the formation of the species-specific food habits of different fishes, as well as individual variations in food intake and utilization from first feeding (Liang et al., 2011). The information from the present study will provide a better understanding of the individual differences of acceptance of formulated diets in a class I endangered species, and allow future development of tools for improving the culture of this species and, perhaps, other species of teleost bony fishes.

In conclusion, it is very important to investigate the reasons for the large differences in individual performance of food acceptance when using formulated diets, for the successful culture of Chinese sturgeon larvae and juveniles. We demonstrated that one SNP each in the LPL and HL genes, as well as one variable site in the mitochondrial DNA control region, showed close association with the acceptance of formulated diet, which proved that the impact of the genetic factor must also be considered in learned behavior.

\section{ACKNOWLEDGMENTS}

Research supported by the Key Laboratory of Freshwater Biodiversity Conservation and Utilization, Ministry of Agriculture of China, Yangtze River Fisheries Research Institute, Chinese Academy of Fishery Sciences (\#LFB20070604), and the Scientific Research Foundation for Returned Overseas Chinese Scholars.

\section{REFERENCES}

Brown JA (1985). The adaptive significance of behavioural ontogeny in some centrarchid fishes. Environ. Biol. Fish. 13: 25-34.

Carton AG (2005). The impact of light intensity and algal-induced turbidity on first-feeding Seriola lalandi larvae. Aquaculture Res. 36: 1588-1594.

Carvalho PSM, Noltie DB and Tillitt DE (2004). Biochemical, histological and behavioural aspects of visual function during early development of rainbow trout. J. Fish Biol. 64: 833-850.

Cooper DA, Stein JC, Strieleman PJ and Bensadoun A (1989). Avian adipose lipoprotein lipase: cDNA sequence and reciprocal regulation of mRNA levels in adipose and heart. Biochim. Biophys. Acta 1008: 92-101.

Hara TJ (2006). Feeding behaviour in some teleosts is triggered by single amino acids primarily through olfaction. J. Fish Biol. 68: 810-825.

Jackson AC, Rundle SD, Attrill MJ and Cotton PA (2004). Ontogenetic changes in metabolism may determine diet shifts for a sit-and-wait predator. J. Anim. Ecol. 73: 536-545.

Liang XF, Lin X, Li S and Liu JK (2008). Impact of environmental and innate factors on the food habit of Chinese perch Siniperca chuatsi (Basilewsky) (Percichthyidae). Aquaculture Res. 39: 150-157.

Liang XF, Xiao H, Wen H and Wei QW (2011). Sensory variability in Chinese sturgeon in relation to fish feeding experience on formulated diets. J. Appl. Ichthyol. 27: 733-736.

Mead JR, Irvine SA and Ramji DP (2002). Lipoprotein lipase: structure, function, regulation, and role in disease. J. Mol. Med. 80: 753-769.

Mukherjee M (2003). Human digestive and metabolic lipases - a brief review. J. Mol. Catal. B Enzymatic 22: 369-376.

Peňa R, Dumas S, Saldivar-Lucio R, García G, et al. (2004). The effect of light intensity on first feeding of the spotted sand bass Paralabrax maculatofasciatus (Steindachner) larvae. Aquaculture Res. 35: 345-349.

Qian X, Cui Y, Xie S, Lei W, et al. (2002). Individual variations in growth, food intake and activity in juvenile Chinese sturgeon Acipenser sinensis Gray. J. Appl. Ichthyol. 18: 695-698.

Raisonnier A, Etienne J, Arnault F, Brault D, et al. (1995). Comparison of the cDNA and amino acid sequences of lipoprotein-lipase in eight species. Comp. Biochem. Physiol. B Biochem. Mol. Biol. 111: 385-398.

Santamarina-Fojo S, Haudenschild C and Amar M (1998). The role of hepatic lipase in lipoprotein metabolism and atherosclerosis. Curr. Opin. Lipidol. 9: 211-219. 
Semenkovich CF, Chen SH, Wims M, Luo CC, et al. (1989). Lipoprotein lipase and hepatic lipase mRNA tissue specific expression, developmental regulation, and evolution. J. Lipid Res. 30: 423-431.

Snickars M, Sandström A and Mattila J (2004). Antipredator behaviour of 0+ year Perca fluviatilis: effect of vegetation density and turbidity. J. Fish Biol. 65: 1604-1613.

Stoner AW (2004). Effects of environmental variables on fish feeding ecology: implications for the performance of baited fishing gear and stock assessment. J. Fish Biol. 65: 1445-1471.

Warburton K (2003). Learning of foraging skills by fish. Fish and Fisheries 4: 203-215.

Wei Q, Ke F, Zhang J, Zhuang P, et al. (1997). Biology, fisheries, and conservation of sturgeons and paddlefish in China. Environ. Biol. Fish. 48: 241-255.

Wong H and Schotz MC (2002). The lipase gene family. J. Lipid Res. 43: 993-999.

Xiao H, Cui Y, Hung SSO, Zhu X, et al. (1999). Growth of juveniles of Chinese sturgeon Acipenser sinensis fed live and formulated diets. North Am. J. Aquaculture 61: 184-188. 